Revue d'histoire de l'Amérique française

REYUE D.HISTOIRE DE L'AMÉRIQUE FRANÇAISE

\title{
LES CLERCS DE SAINT-VIATEUR, L'Histoire chez les petits. Montréal, 1951. 154 pages. Guide méthodologique pour l'enseignement de l'histoire du Canada en première année
}

\section{Gustave Bellefleur}

Volume 5, numéro 3, décembre 1951

URI : https://id.erudit.org/iderudit/801728ar

DOI : https://doi.org/10.7202/801728ar

Aller au sommaire du numéro

Éditeur(s)

Institut d'histoire de l'Amérique française

ISSN

0035-2357 (imprimé)

1492-1383 (numérique)

Découvrir la revue

Citer ce compte rendu

Bellefleur, G. (1951). Compte rendu de [LES CLERCS DE SAINT-VIATEUR, L'Histoire chez les petits. Montréal, 1951. 154 pages. Guide méthodologique pour l'enseignement de l'histoire du Canada en première année]. Revue d'histoire de l'Amérique française, 5(3), 439-439.

https://doi.org/10.7202/801728ar d'utilisation que vous pouvez consulter en ligne. 
Leg Clercs de Saint-Viateur, L'Histoire chez les petits. Montréal, 1951. 154 pages. Guide méthodologique pour l'enseignement de l'histoire du Canada en première année.

Excellent "Guide" que celui-ci et bien conforme à l'esprit du nouveau programme. Renseignements indispensables, questions, dramatisation, remarques, activités, entretiens, commentaires, rien ne manque. Peut-otre y aurait-il quelques expressions à corriger. Pour ne donner qu'un exemple, p. 113: "On ne fait pas un prêtre", mais "on se fait" ou "on devient prêtre". Quant au fond, au ton, rien à reprendre.

Depuis quelques années, plusieurs brochures ou volumes ont été đ́dités sur l'éducation patriotique. Mentionnons, en particulier, un catéchisme des Frères du Sacre-Cœur publié en 1937: L'éducation nationale à l'école. Nos revues pédagogiques ont publié un grand nombre d'articles sur le sujet. Ces dernières années, plusieurs éducateurs et des communautés religieuses, entre autres, les Frères des Écoles Chrétiennes et les Frères de l'Instruction chrétienne, ont mis sur le marché des Albums d'histoire pour les tout jeunes. Tout dernièrement, la "Société des Écrivains pour la jeunesse" publiait un catalogue de livres canadiens où l'éducation nationale occupe une grande place. Au quatrième congrès de l'A.C.E.L.F., tenu cet été à l'Université Saint-Joseph de Memramcook, nous entendions une magnifique conférence de M. l'abbé P.-Émile Gosselin sur ce sujet. Ce sera aussi le thème du troisième congrès de la Langue française à Québec en juin 1952. Evidemment la question est à l'ordre du jour. Souhaitons que l'on continue de s'acheminer vers la rédaction de manuels bien faits, attrayants, qui réveleront à notre jeunesse la beauté du passé canadien et lui inspireront de le mieux connaitre. 